\title{
Characterizing post-extubation negative pressure pulmonary edema in the operating room-a retrospective matched case-control study
}

\author{
Pei-Hsin Tsai ${ }^{1,2}$, Jen-Hung Wang ${ }^{3}$, Shian-Che Huang ${ }^{1}$, Yen-Kuang Lin $^{4}$ and Chen-Fuh Lam ${ }^{1 *}$
}

\begin{abstract}
Background: Post-extubation negative pressure pulmonary edema (NPPE) is an uncommon but important anesthesiarelated emergency presenting with acute respiratory distress and hypoxemia after removal of airway devices. This study investigated the incidence and associated risk factors for post-extubation NPPE during emergence.

Methods: This retrospective, matched case-control study was conducted by reviewing the post-anesthesia records in Tzu Chi General Hospital, Taiwan. Patients reported of having acute hypoxemia $\left(\mathrm{SpO}_{2}<92 \%\right)$ shortly after the removal of the endotracheal tube or supraglottic airway, associating with radiographic evidence of pulmonary edema and/or pink frothy sputum, were identified as definite NPPE cases. The potential risk factors were compared with the matched controls, who were randomly selected from the same database.

Results: A total of 85,561 patients received general anesthesia with airway instrumentation during the 8.5-year study period. A total of 16 patients were identified as definite cases of NPPE. Compared with the matched controls $(n=131)$, males, active smokers, emergency operation, endotracheal intubation, use of desflurane, and prolonged operation time carried significantly higher risks of developing NPPE $(P<0.05)$. Multivariate logistic regression analysis illustrated that active smoking (AOR 7.66, 95\% Cl 1.67-35.3; $P=0.009$ ) and endotracheal intubation (AOR 10.87, 95\% Cl 1.23-100; $P=0.03)$ were the two most significant independent variables of post-extubation NPPE.

Conclusion: We present the first clinical comparative study demonstrating that the overall incidence of NPPE immediately after extubation in the operating room is $0.019 \%$. Our results highlight that active smokers and patients receiving endotracheal intubation general anesthesia are associated with significantly higher risks of developing NPPE following extubation in the operating room.
\end{abstract}

Keywords: Upper airway obstruction, Respiratory complication, Extubation failure

\section{Background}

Post-extubation negative pressure pulmonary edema (NPPE) or post-obstructive pulmonary edema (POPE) occurs following a large negative intrathoracic pressure generated by forceful inspiration against an obstructed airway, such as laryngospasm or mechanical obstruction (Lemyze and Mallat 2014). The generation of extremely high negative intrapleural pressure significantly increases the

\footnotetext{
* Correspondence: ed110208@edah.org.tw

${ }^{1}$ Department of Anesthesiology, E-Da Hospital/E-Da Cancer Hospital, I-Shou University, No 1, Yida Road. Yanchao Dist., Kaohsiung city 824, Taiwan Full list of author information is available at the end of the article
}

pulmonary capillary permeability and enhances venous return into the right heart, leading to fluid translocation from intravascular system to the pulmonary interstitium (Lang et al. 1990). During the emergence phase of anesthesia, NPPE most commonly happens in patients with acute laryngospasm following the removal of an endotracheal tube or supraglottic airways (Lorch and Sahn 1968; Ghofaily et al. 2013). The onset of pulmonary edema is usually rapid (within a few minutes after signs of upper airway obstruction) and presents with hypoxemia and acute pulmonary edema (radiographic changes in the chest and pink frothy hemoptysis) (Lemyze and Mallat 2014; Ghofaily et al.

(c) The Author(s). 2018 Open Access This article is distributed under the terms of the Creative Commons Attribution 4.0 International License (http://creativecommons.org/licenses/by/4.0/), which permits unrestricted use, distribution, and 
2013). In general, NPPE is usually a benign condition typically resulting in full recovery within $12-48 \mathrm{~h}$ (Krodel et al. 2010). However, it can be a true post-anesthesia emergency that requires immediate tracheal re-intubation, and up to $50 \%$ of these patients are subjected to prolonged mechanical ventilatory support due to acute respiratory failure (Krodel et al. 2010; McConkey 2000).

The estimated incidence of post-extubation NPPE is approximately $0.01-0.1 \%$ during general anesthesia (Krodel et al. 2010; McConkey 2000; Deepika et al. 1997; Bhaskar and Fraser 2011). In a retrospective case-control study, NPPE were more frequently reported in healthy (ASA physical status I and II), middle-aged, and male patients (Deepika et al. 1997). Since NPPE is a rare post-anesthesia event, there are currently no large-scale comparative clinical studies available in the literature. In addition, the incidence and the precipitating factors of post-anesthesia NPPE are difficult to compute from the case series data or descriptive studies (Bhattacharya et al. 2016). Therefore, we performed a retrospective, matched case-control study to analyze the overall incidence and the associated risk factors of post-extubation NPPE during the emergence period of anesthesia from the database of post-anesthesia records in our hospital.

\section{Methods}

\section{Patient database}

This retrospective chart review study carried out in a tertiary teaching medical center located at Hualien City of Taiwan that consists of 945 beds. The study was approved by the ethics committee and the institutional review board (IRB, Approval number IRB106-22-B), and the requirement for written informed consent was waived by the ethics committee. All surgical patients received endotracheal general anesthesia (ETGA) or laryngeal mask anesthesia (LMA) during 1 January 2008 to 31 May 2016 were included in this study, except for those who received intravenous sedation without airway instrumentation and removal of airway devices in medical care units other than operation room (Fig. 1). Active smoker was defined as a patient who actively smoked at least one cigarette a day within the preceding week of surgery (Warner et al. 2004).

\section{Definition of post-extubation NPPE}

Post-extubation NPPE was defined as the development of acute hypoxemia (pulse oximetry, $\mathrm{SpO}_{2}<92 \%$ ) with witnessed signs of upper airway obstruction by the anesthetists after removal of an endotracheal tube or laryngeal mask airway in the operation room. Definite cases of NPPE should also coexist with evidence of chest radiography of newly occurred pulmonary edema and/or cough with pink frothy sputum (Ghofaily et al. 2013).

\section{Matched controls}

Matched controls were surgical patients who received ETGA or LMA intervention without developing desaturation and

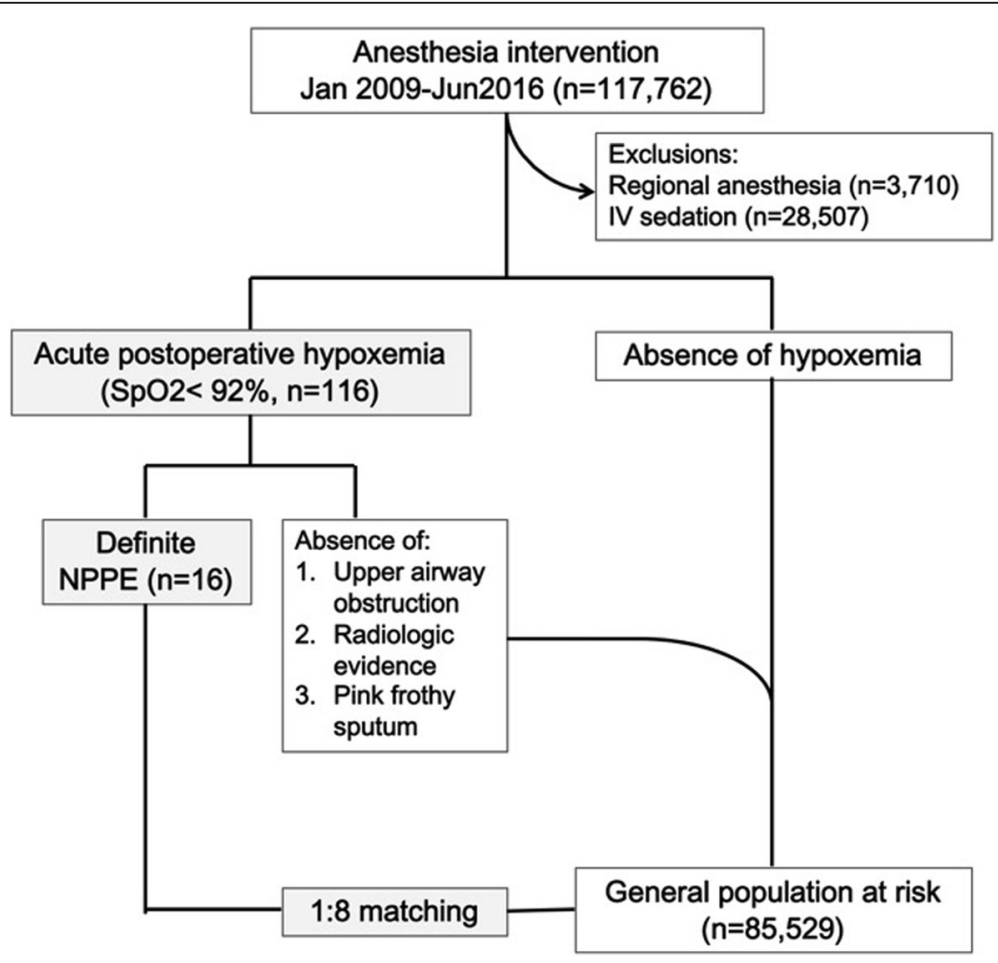

Fig. 1 Study design and matching of case-controls 
clinical signs of pulmonary edema during the study period. These patients were randomly selected from the same database after matching with the calendar year of operation in a $1: 8$ ratio.

\section{Statistics}

The potential categorical and numerical risk factors of occurrence of NPPE were compared with the matched case-control patients who did not develop NPPE by the chi-square and Wilcoxon signed-rank tests, respectively. A conditional logistic regression model was adopted to evaluate the association between these risk factors and NPPE. Statistical significance was accepted at a level of $P<0.05$. All statistical analyses were performed using SAS 9.4 (SAS Institute, Cary, NC).

\section{Results}

There were a total of 117,762 patients who received anesthesia management during the 8.5-year period in our hospital, and 85,545 of these surgical patients were anesthetized with an endotracheal tube (ETGA) or laryngeal mask (LMA) (Fig. 1). Since perioperative desaturation $\left(\mathrm{SpO}_{2}<\right.$ $92 \%$ ) is an imperative quality assurance parameter that has been consistently monitored in our hospital, all cases who developed desaturation during the emergence period were reviewed. A total of 116 patients were recorded to experience desaturation during the study period, and 16 patients were identified as definite cases of NPPE shortly after the removal of airway devices in the operating room (Table 1). Most of these patients (9/16) were transferred to the intensive care unit (ICU) after the unexpected event, and 1 patient eventually expired 50 days later due to uncontrollable postoperative pulmonary complication and development of multiple system organ failure (Table 1).

Compared with the matched controls $(n=131)$, patients who developed post-extubation NPPE were younger (49.4 \pm 19.7 vs $45.1 \pm 18.1$ years, respectively; $P=0.065$ ), male gender predominant (61/131 vs $10 / 16$, respectively; $P<0.001)$, and consisted of higher proportion of active smoker (26/131 vs $9 / 16$, respectively; $P<0.001$ ) (Tables 2 and 3 ). The body mass index (BMI) of the post-extubation NPPE patients was significantly lower, but levels of ASA physical status were not different between the two groups (Tables 2 and 3).

The significantly higher proportion of patients who developed post-extubation NPPE received emergency operation $(16 / 131$ vs $4 / 19 ; P=0.003)$, and the operation time was prolonged in these patients $(148.4 \pm 92.1 \mathrm{~min}$ vs $167.2 \pm 103.8 \mathrm{~min} ; P=0.022$ ) (Tables 2 and 3). With longer operation time, the total intravenous fluid administration, urine output, and estimated blood loss during the perioperative period were also increased in the post-extubation NPPE group (Table 2). The total doses of morphine administrated intravenously for perioperative pain control were not different (Table 2). In comparison to the matched case-controls, the statistical analysis showed that proportion of patients anesthetized with ETGA and use of desflurane were significantly increased in the post-extubation NPPE group $(P<0.001$ and $P=$ 0.016 , respectively; Table 3$)$. There were no significant differences between body sites of operation (such as upper airway surgery vs surgery on other body parts) and the post-extubation NPPE (Additional file 1: Table S1).

These patient's characteristic and surgery-related and anesthesia-related risk factors that associated with post-extubation NPPE were further analyzed by multivariate logistic regression. Male gender and use of desflurane became not significantly different in the development of NPPE following the removal of the endotracheal tube and laryngeal mask (Table 4). Most importantly, active smoking [adjusted odds ratio (AOR) 7.66, 95\% CI 1.67-35.3; $P=0.009$ ] and endotracheal intubation (AOR 10.87, 95\% CI 1.23-100; $P=0.03$ ) were identified as the two independent variables that are significantly associated with the occurrence of post-extubation NPPE in the operating room (Table 4).

\section{Discussion}

The foremost important clinical message addressed in this study is that post-extubation NPPE is a relatively rare complication in the operating room with an overall incidence of $0.019 \%(\approx 19$ cases in 100,000 general anesthesia with airway instrumentation), but it results in increased extraneous medical cost, as $56 \%$ of patients who developed unexpected NPPE after extubation were admitted to ICU for postoperative care, and it also engendered to a case of mortality in this study. Therefore, the recognition of the associated risk factors is essential to enhance our ability to prevent the development of NPPE following extubation of airway instruments in the operating room during the emergence period.

Dr. Deepika et al. reported one of the largest scale case series studies in patients developed NPPE in the operating rooms, post-anesthesia care units (PACU), and ICU after surgery (Deepika et al. 1997). The overall incidence of post-extubation NPPE was $0.094 \%$ (30 cases in 31,826 surgical patients) in their clinical case review (Deepika et al. 1997). A similar incidence of $0.084 \%$ (14 cases in 16,653 surgical patients) was reported during orthopedic surgery that eventually developed post-extubation NPPE (Patton and Baker Jr 2000). In light of the total number of cases reviewed, site of extubation, defined inclusion criteria, and study population, we believe that the overall incidence of $0.019 \%$ reported in our study is reasonably close to these previous case review studies. Hence, the results of our study are applicable to the general surgical population who received anesthesia with ETGA or LMA and anticipated to extubate in the operating room after surgery.

Several perioperative risk factors of post-extubation NPPE have been proposed, including patients of younger 


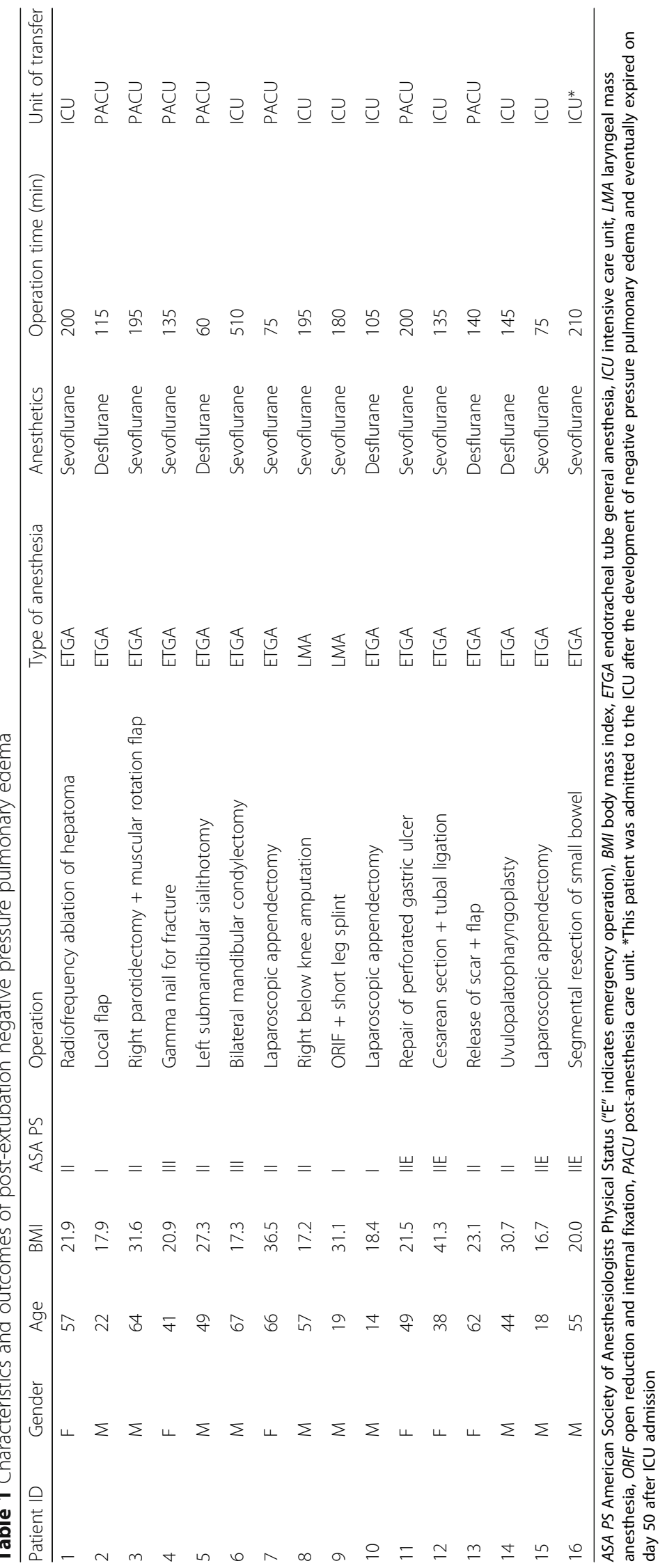


Table 2 Characteristic analysis of the categorical risk factors associated with post-extubation negative pressure pulmonary edema (NPPE)

\begin{tabular}{|c|c|c|c|c|c|}
\hline \multirow{2}{*}{$\begin{array}{l}\text { Categorical } \\
\text { variables }\end{array}$} & \multicolumn{2}{|c|}{ Case $(n=16)$} & \multicolumn{2}{|c|}{ Matched controls $(n=131)$} & \multirow[t]{2}{*}{$P$ value } \\
\hline & $n$ & $\%$ & $n$ & $\%$ & \\
\hline Male & 10 & 62.5 & 61 & 46.6 & $<0.001^{*}$ \\
\hline \multicolumn{5}{|l|}{ ASA PS } & \multirow[t]{3}{*}{0.174} \\
\hline$|-| \mid$ & 14 & 87.5 & 101 & 77.1 & \\
\hline III-IV & 2 & 12.5 & 30 & 22.9 & \\
\hline \multicolumn{6}{|c|}{ Emergency operation } \\
\hline Yes & 4 & 25.0 & 16 & 12.2 & $0.003^{*}$ \\
\hline \multicolumn{5}{|c|}{ Anesthetic technique } & \multirow[t]{3}{*}{$<0.001^{*}$} \\
\hline ETGA & 14 & 87.5 & 85 & 64.9 & \\
\hline LMA & 2 & 12.5 & 46 & 35.1 & \\
\hline \multicolumn{6}{|l|}{ Difficult airway } \\
\hline Yes & 0 & 0 & 17 & 13.0 & $<0.001^{*}$ \\
\hline \multicolumn{5}{|c|}{ Type of inhaled anesthetic } & \multirow[t]{3}{*}{$0.016^{*}$} \\
\hline Desflurane & 5 & 31.3 & 18 & 13.7 & \\
\hline Sevoflurane & 11 & 68.7 & 107 & 81.7 & \\
\hline \multicolumn{6}{|l|}{ Active smoker } \\
\hline Yes & 9 & 56.3 & 26 & 20.0 & $<0.001^{*}$ \\
\hline
\end{tabular}

ASA PS American Society of Anesthesiologists Physical Status, ETGA endotracheal tube general anesthesia, $L M A$ laryngeal mask anesthesia. Data were analyzed by chi-square test and are shown as number (percent). ${ }^{*} P<0.05$ is considered statistically significant

age, male, generally healthy (ASA I-II), difficult intubation, use of irritant volatile agents, operation on the head and neck region, obese, and recent upper airway infection (Lang et al. 1990; Lorch and Sahn 1968; Ghofaily et al. 2013; Krodel et al. 2010; McConkey 2000; Deepika et al. 1997; Bhaskar and Fraser 2011; Scarbrough et al. 1997). However, none of these factors has been characterized in a comparative analysis manner. In this study, we randomly selected non-case controls from the same database after matching with the calendar year of operation, as different time points of operation over the 8.5 years of study period might confound the outcome analysis (Rose and Laan 2009). Compared with the matched controls, univariate analysis demonstrated that the numbers of male gender, active smoker, and lower BMI (all $P<0.001$ ) were significantly higher in the post-extubation NPPE group, while the incidence was marginally increased in younger age $(P=0.065)$, and there was no difference in ASA physical statuses $(P=$ 0.174). These findings are consistent with the general idea that young, healthy males are more likely to generate greater inspiratory force to induce extraordinarily high negative intrapleural pressure for the shifting of lung interstitial fluid when the upper airway is occluded secondary to laryngospasm or obstruction following the removal of airway device (Krodel et al. 2010; Scarbrough et al. 1997). In line with some previous studies, our analysis did not find obesity contributes to increased risk of NPPE (Mulkey et al. 2008) but speculated that smoking is strongly associated with the occurrence of post-extubation NPPE (Mulkey et al. 2008). Smoking increases the upper airway reflex sensitivity (Erskine et al. 1994) and has been widely recognized as an independent risk factor of postoperative adverse events on the upper airway, which carries relative risks of 1.8 in all smokers and 2.3 in young smokers (16-39 years) (Schwilk et al. 1997).

The associations between post-extubation NPPE and anesthesia-related variables were analyzed in this study. Anesthesia with endotracheal intubation (ETGA) and the use of desflurane as an inhaled anesthetic agent are highly correlated with the occurrence of NPPE after extubation. The study did not find patients who eventually developed post-extubation NPPE and were documented as cases of difficult airway during the induction phase of anesthesia. Anesthesia with a laryngeal mask has been proven to reduce the incidence of laryngospasm during the emergence phase of anesthesia in the general population ( $\mathrm{Yu}$ and Beirne 2010) and infants (Drake-Brockman et al. 2017). Therefore, more invasive airway manipulation using an endotracheal tube is inevitably associated with a higher incidence of laryngospasm and, subsequently, the development of post-extubation NPPE compared with LMA. Inhaled desflurane is generally considered to induce more upper airway response than sevoflurane during the perioperative period (Arain et al. 2005). However, recent studies indicate that the respiratory events were not increased with the use of desflurane considering the concentrations of anesthetic gas are carefully titrated (Stevanovic et al. 2015). In fact, cigarette smoking, but not the choice of anesthetic agents (desflurane vs sevoflurane), increases the risk of respiratory complications after operation (McKay et al. 2006). Furthermore, desflurane may provide a more rapid emergence and recovery profile that enhance its application in prolonged operation with anticipating extubation in the operating room (McKay et al. 2006). Therefore, the direct relationship between a particular anesthetic gas and post-extubation NPPE is not possible to establish using the univariate analysis. Our study also investigated the potential contribution of surgical-related factors and identified that emergency operation and prolonged operation time are the two notable risk factors associated with the development of post-extubation NPPE. Interestingly, there were four emergency operation patients who developed NPPE after extubation, and they all received ETGA anesthesia, reinforcing our above findings that LMA anesthesia is less irritable in the airway. The site of operation is another risk factor that has been frequently discussed, as some studies found NPPE occurred more often in the head and neck surgery (Deepika et al. 1997), while others did not (Mulkey et al. 2008). In the present study, we did not find significant effects of surgical sites on the occurrence of NPPE. 
Table 3 Characteristic analysis of the numerical risk factors associated with post-extubation negative pressure pulmonary edema (NPPE)

\begin{tabular}{llll}
\hline Numerical variables & Case & Matched controls & $P$ value \\
\hline Age & $45.1 \pm 18.1$ & $49.4 \pm 19.7$ & 0.065 \\
Body mass index & $24.6 \pm 7.6$ & $25.1 \pm 5.3$ & $<0.001^{*}$ \\
Duration of operation $(\mathrm{min})$ & $167.2 \pm 103.8$ & $148.4 \pm 92.1$ & $0.022^{*}$ \\
Intraoperative morphine $(\mathrm{mg})$ & $2.0 \pm 2.9$ & $3.1 \pm 9.6$ & 0.247 \\
Intraoperative fluid (ml) & $1456.3 \pm 906.3$ & $1040.4 \pm 947.5$ & $<0.001^{*}$ \\
Intraoperative urine output (ml) & $256.3 \pm 394.5$ & $147.8 \pm 286.8$ & $0.004^{*}$ \\
Estimated blood loss $(\mathrm{ml})$ & $156.3 \pm 272.4$ & $128.3 \pm 272.8$ & 0.091 \\
\hline
\end{tabular}

Data were analyzed by Wilcoxon signed-rank test and are shown as mean \pm SD. ${ }^{*} P<0.05$ is considered statistically significant

Models of multivariate logistic regression were used in this study to identify the dominant variables associated with post-extubation NPPE. Only two measurement variables were found as strong independent risk factors of NPPE in the operating room, namely active smoking and ETGA, with AORs of 7.66 (95\% CI 1.67-35.3; $P=0.009)$ and 10.87 (95\% CI 1.23-100; $P=0.03$ ), respectively. Although the other variables failed to demonstrate statistically significant differences in multivariate regression analysis, we specify that male gender, younger age, and prolonged operation should be considered as precipitating factors in the development of NPPE in the operating room, especially in active smokers and patients receiving endotracheal intubation.

There are several limitations in this study. First, the retrospective study design limits the ability to establish any direct causal relationships between the measured variables and post-extubation NPPE. Since the incidence of post-extubation NPPE is relatively very rare, matched case-control study design rather than propensity matching was used to identify

Table 4 Multivariate conditional logistic regression analysis

\begin{tabular}{lllll}
\hline Risk factors & AOR & $95 \% \mathrm{Cl}$ & $x^{2}$ & $P$ \\
\hline Gender & & & & \\
$\quad$ Male vs female & 1.31 & $0.24-7.12$ & 0.09 & 0.75 \\
$\begin{array}{l}\text { Age (years) } \\
\text { Smoking }\end{array}$ & 1.02 & $0.98-1.05$ & 0.96 & 0.33 \\
$\quad$ Yes vs no & 7.68 & $1.67-35.36$ & 6.85 & $0.009^{*}$ \\
$\quad \begin{array}{l}\text { Type of anesthetics } \\
\quad \text { Des vs Sevo }\end{array}$ & 0.73 & $0.17-3.14$ & 0.18 & 0.67 \\
$\begin{array}{l}\text { Anesthesia technique } \\
\quad \text { ETGA vs LMA }\end{array}$ & 10.87 & $1.23-100$ & 4.60 & $0.03^{*}$ \\
$\quad \begin{array}{l}\text { Duration of operation (min) } \\
\text { Intraoperative fluid (ml) }\end{array}$ & 1.00 & $0.99-1.02$ & 0.11 & 0.73 \\
\hline
\end{tabular}

Multivariate conditional logistic regression model was adopted to evaluate the association between the potential risk factors and the development of POPE. $A O R$ adjusted odds ratio, $\mathrm{Cl}$ confidence interval, Des desflurane, ETGA endotracheal general anesthesia, LMA laryngeal mask anesthesia, Sevo sevoflurane, $X^{2}$ chi-square analysis. Smoking was defined as actively smoking at least one cigarette a day within the preceding week of surgery. ${ }^{*} P<0.05$ is considered as statistical significant the associated risk factors, resulting in a large range of data variance. Nevertheless, propensity matching of patient or surgical characteristics (such as age, gender, ASA classification, or types of surgery) might in fact introduce confounding effects to the analysis (Pearce 2016), as these characteristics could be the independent risk factors of NPPE. This study is also subject to potential missing cases from medical chart review. However, perioperative hypoxemia $\left(\mathrm{SpO}_{2}<92 \%\right)$ is one of the key clinical parameters for monitoring of anesthesia quality assurance in our institute with an overall incidence of $0.13 \%$ in patients who received ETGA or LMA anesthesia. Therefore, it would be very unlikely that clinically severe hypoxemia cases after extubation in the operating room were undetected in our anesthesia records. Nevertheless, those who developed subclinical degrees of NPPE $\left(\mathrm{SpO}_{2} \geq 92 \%\right)$ were not included in this report, as chest radiography is not routinely taken in the operating room or PACU with the absence of signs of clinical hypoxemia. Although smoking has been identified as an independent risk factor for post-extubation NPPE, duration of smoking and the amount of cigarettes consumed each day were not taken into the analysis. Finally, this study did not include other potential risk factors, such as recent symptoms of upper airway infection or asthma, as these information were not comprehensively recorded in each pre-anesthesia assessment file.

\section{Conclusion}

We present the first comparative clinical study reporting the incidence and risk factors for NPPE during the emergence phase of anesthesia in the operating room. The overall incidence of post-extubation NPPE in the operating room is about $0.019 \%$. Multivariate logistic regression analysis indicates that active smokers and anesthesia with ETGA are the two most important independent risk factors for developing NPPE in the post-anesthesia setting. We also highlight that male gender, younger age, and prolonged operation time should be considered as precipitating factors in the development of NPPE in the operating room, especially in active smokers and patients receiving endotracheal intubation. 


\section{Additional file}

Additional file 1: Table S1. Characteristic analysis of the body parts (sites) of operation associated with post-extubation negative pressure pulmonary edema (NPPE). (DOCX $65 \mathrm{~kb}$ )

\section{Abbreviations}

AOR: Adjusted odds ratio; ASA: American Society of Anesthesiologists; BMI: Body mass index; ETGA: Endotracheal intubation general anesthesia; ICU: Intensive care unit; IRB: Institutional review board; LMA: Laryngeal mask anesthesia; NPPE: Negative pressure pulmonary edema; POPE: Postobstructive pulmonary edema

\section{Acknowledgements}

The authors wish to express their deepest gratitude to Ms. Xiu-Zhu Liu and Shiu-Ying Hsieh (Department of Anesthesiology, Hualien Tzu Chi General Hospital, Taiwan) for the assistance in data processing and preparation of the manuscript.

\section{Funding}

This work was supported by research grants obtained from the Ministry of Science and Technology, Taiwan (grant number MOST 105-2314-B-303-007MY2 to CFL). The funders had no role in study design, data collection and analysis, decision to publish, or preparation of the manuscript.

\section{Availability of data and materials}

The data and materials used in the study are available on request from the corresponding author.

\section{Authors' contributions}

PHT contributed to the data collection, clinical case analysis, study conception, and writing of the article. JHW and YKL performed the data analysis and interpretation. SCH contributed to the study conception, study design, data analysis, and preparation of the article. CFL conceived the study and participated in its design and coordination. All authors read and approved the final manuscript.

\section{Ethics approval and consent to participate}

The study was approved by the institutional review board (approval number IRB106-22-B) at the Buddhist Tzu Chi General Hospital, Hualien, Taiwan. Ethical approval was granted according to the Taiwan government's requirements, and the need for written informed consent was waived.

\section{Consent for publication}

Not applicable

\section{Competing interests}

The authors declare that they have no competing interests.

\section{Publisher's Note}

Springer Nature remains neutral with regard to jurisdictional claims in published maps and institutional affiliations.

\section{Author details}

${ }^{1}$ Department of Anesthesiology, E-Da Hospital/E-Da Cancer Hospital, I-Shou University, No 1, Yida Road. Yanchao Dist., Kaohsiung city 824, Taiwan. 2Department of Anesthesiology, Buddhist Tzu Chi General Hospital, Hualien, Taiwan. ${ }^{3}$ Department of Medical Research, Tzu Chi General Hospital, Hualien, Taiwan. ${ }^{4}$ Biostatistics Center, Taipei Medical University, Taipei, Taiwan.

Received: 16 August 2018 Accepted: 10 October 2018

Published online: 06 December 2018

\section{References}

Arain SR, Shankar H, Ebert TJ. Desflurane enhances reactivity during the use of the laryngeal mask airway. Anesthesiology. 2005;103:495-9.

Bhaskar B, Fraser JF. Negative pressure pulmonary edema revisited: pathophysiology and review of management. Saudi J Anaesth. 2011;5: 308-13.
Bhattacharya M, Kallet RH, Ware LB, Matthay MA. Negative-pressure pulmonary edema. Chest. 2016:150:927-33.

Deepika K, Kenaan CA, Barrocas AM, Fonseca JJ, Bikazi GB. Negative pressure pulmonary edema after acute upper airway obstruction. J Clin Anesth. 1997:9:403-8.

Drake-Brockman TF, Ramgolam A, Zhang G, Hall GL, von Ungern-Sternberg BS. The effect of endotracheal tubes versus laryngeal mask airways on perioperative respiratory adverse events in infants: a randomised controlled trial. Lancet. 2017;389:701-8.

Erskine RJ, Murphy PJ, Langton JA. Sensitivity of upper airway reflexes in cigarette smokers: effect of abstinence. Br J Anaesth. 1994;73:298-302.

Ghofaily LA, Simmons C, Chen L, Liu R. Negative pressure pulmonary edema after laryngospasm: a revisit with a case report. J Anesth Clin Res. 2013;3:252

Krodel DJ, Bittner EA, Abdulnour R, Brown R, Eikermann M. Case scenario: acute postoperative negative pressure pulmonary edema. Anesthesiology. 2010; 113:200-7.

Lang SA, Duncan PG, Shephard DA, Ha HC. Pulmonary oedema associated with airway obstruction. Can J Anaesth. 1990;37:210-8.

Lemyze M, Mallat J. Understanding negative pressure pulmonary edema. Intensive Care Med. 2014:40:1140-3.

Lorch DG, Sahn SA. Post-extubation pulmonary edema following anesthesia induced by upper airway obstruction. Are certain patients at increased risk? Chest. 1968;90:802-5

McConkey PP. Postobstructive pulmonary oedema - a case series and review. Anaesth Intensive Care. 2000;28:72-6.

McKay RE, Bostrom A, Balea MC, McKay WR. Airway responses during desflurane versus sevoflurane administration via a laryngeal mask airway in smokers. Anesth Analg. 2006;103:1147-54.

Mulkey Z, Yarbrough S, Guerra D, Roongsritong C, Nugent K, Phy MP. Postextubation pulmonary edema: a case series and review. Respir Med. 2008;102:1659-62.

Patton WC, Baker CL Jr. Prevalence of negative-pressure pulmonary edema at an orthopaedic hospital. J South Orthop Assoc. 2000:9:248-53.

Pearce N. Analysis of matched case-control study. BMJ. 2016;352:1969.

Rose S, Laan MJ. Why match? Investigating matched case-control study designs with causal effect estimation. Int J Biostat. 2009;5:article 1.

Scarbrough FE, Wittenberg JM, Smith BR, Adcock DK. Pulmonary edema following postoperative laryngospasm: case reports and review of the literature. Anesth Prog. 1997:44:110-6.

Schwilk B, Bothner U, Schraag S, Georgieff M. Perioperative respiratory events in smokers and nonsmokers undergoing general anaesthesia. Acta Anaesthesiol Scand. 1997:41:348-55.

Stevanovic A, Rossaint R, Fritz HG, Froeba G, Heine J, Puehringer FK, Tonner PH, Coburn M. Airway reactions and emergence times in general laryngeal mask airway anaesthesia: a meta-analysis. Eur J Anaesthesiol. 2015;32:106-16.

Warner DO, Patten CA, Ames SC, Offord K, Schroeder D. Smoking behavior and perceived stress in cigarette smokers undergoing elective surgery. Anesthesiology. 2004;100:1125-37.

Yu SH, Beirne OR. Laryngeal mask airways have a lower risk of airway complications compared with endotracheal intubation: a systematic review. J Oral Maxillofac Surg. 2010;68:2359-76.
Ready to submit your research? Choose BMC and benefit from:

- fast, convenient online submission

- thorough peer review by experienced researchers in your field

- rapid publication on acceptance

- support for research data, including large and complex data types

- gold Open Access which fosters wider collaboration and increased citations

- maximum visibility for your research: over $100 \mathrm{M}$ website views per year

At BMC, research is always in progress.

Learn more biomedcentral.com/submissions 